\title{
Partial vaginal expulsion of a leiomyosarcoma
}

\author{
Kaori Yokochia , Noely Paula Cristina Lorenzi ${ }^{a}$, Ricardo dos Santos Simões ${ }^{a}$, \\ Leonardo Gomes Fonsecab ${ }^{b}$ Patrícia Picciarelli de Limac
}

Yokochi K, Lorenzi NPC, Simões RS, Fonseca LG, Lima PP. Partial vaginal expulsion of a leiomyosarcoma. Autopsy Case Rep [Internet]. 2013;3(2):51-58. http://dx.doi.org/10.4322/acr.2013.018

\section{ABSTRACT}

\begin{abstract}
Uterine sarcomas are an uncommon and heterogeneous group of tumors that account for $3-7 \%$ of the malignant neoplasms of the uterus and approximately $1 \%$ of all malignant tumors of the female genital system. The main clinical manifestations are abnormal uterine bleeding in pre- or postmenopausal women. Pelvic pain, abdominal distension, urinary urgency, and profuse and fetid leukorrhea are other frequent complaints. The authors present a case of a 48-year-old patient that was in amenorrhea for 2 years, who sought treatment for vaginal bleeding. On physical examination, the abdomen was distended, painful in the hypogastrium and upon examination of the external genitalia, it was observed the exteriorization of an amorphous "mass". The patient was submitted to uterine curettage. The results of the histological examination revealed leiomyosarcoma. Staging workup showed an enlarged uterus with endometrial lesion, and non-calcified pulmonary nodules. The patient underwent a pan-hysterectomy and chemotherapy, and is under oncologic treatment. The authors call attention for the unusual form of presentation of this entity.
\end{abstract}

Keywords: Leiomyosarcoma; Uterus; Curettage; Hysterectomy; Drug Therapy.

\section{CASE REPORT}

A 48-year-old, married, Caucasian female patient sought the emergency room complaining of vaginal bleeding and vaginal expulsion of a fetid and amorphous material. She referred a recent diagnosis of fibroids. Her past obstetric history included Gravidity 4, Parity 4. Her last menstrual period was 2 years ago.

On physical examination the patient was in good general condition, pale, hydrated, blood pressure $=140 / 90 \mathrm{mmHg}$, weight $=70 \mathrm{~kg}$, height $=150$ $\mathrm{cm}(\mathrm{BMI}=31)$. The abdomen was distended and painful in hypogastrium with an increased uterine volume reaching the umbilical scar. Upon examination of the external genitalia, it was observed the exteriorization of an amorphous "mass," foul-smelling, and pinkish gray, measuring approximately $30 \mathrm{~cm}$ by the vagina (Figure 1).

On speculum examination, the cervix was not able to be identified due to the large amount of expulsed material in the vagina. The bimanual examination was not performed due to technical obstacles. Laboratory tests are shown in Table 1.

\footnotetext{
a Department of Gynecology - Hospital Universitário - Universidade de São Paulo, São Paulo/SP - Brazil.

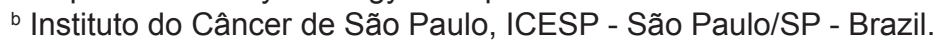

${ }^{c}$ Anatomic Pathology Service - Hospital Universitário - Universidade de São Paulo, São Paulo/SP - Brazil.
} 


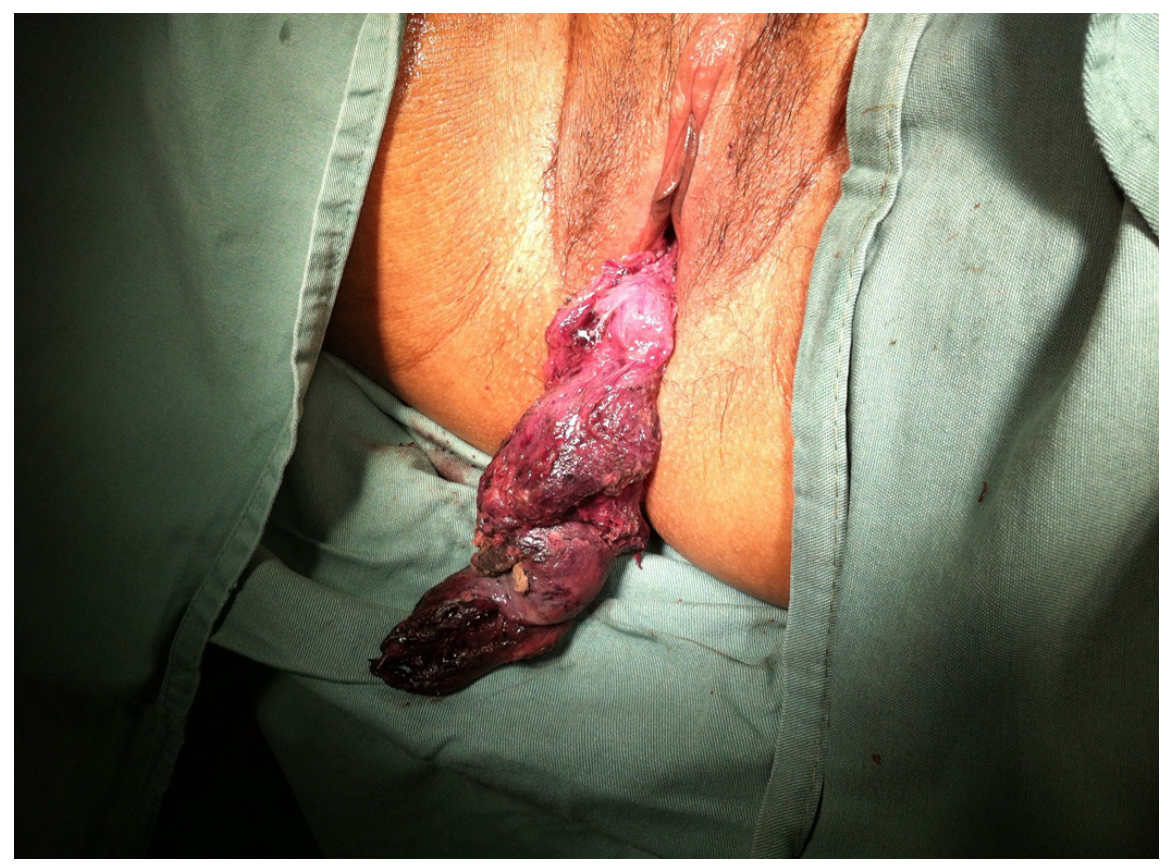

Figure 1 - Vaginal expulsion of a voluminous, amorphous and pinky mass.

Table 1 - Initial laboratory workup

\begin{tabular}{cccccc}
\hline & & RV & & RV \\
\hline Hemoglobin & 10 & $12.3-15.3 \mathrm{~g} / \mathrm{dL}$ & INR & 1.13 & 1.0 \\
Hematocrit & 31.4 & $36.0-45.0 \%$ & Urea & 19 & $5-25 \mathrm{mg} / \mathrm{dL}$ \\
Leucocytes & 9280 & $4.4-11.3 \times 10^{3} / \mathrm{mm}^{3}$ & Creatinine & 0.5 & $0.4-1.3 \mathrm{mg} / \mathrm{dL}$ \\
Bands & 5 & $1-5 \%$ & Potassium & 5.0 & $3.5-5.0 \mathrm{mEq} / \mathrm{L}$ \\
Segmented & 54 & $45-70 \%$ & Sodium & 141 & $136-146 \mathrm{mEq} / \mathrm{L}$ \\
Eosinophils & 0 & $1-4 \%$ & ALT & 10 & $9-36 \mathrm{U} / \mathrm{L}$ \\
Basophils & 0 & $0-2.5 \%$ & AST & 14 & $10-31 \mathrm{U} / \mathrm{L}$ \\
Lymphocytes & 35 & $18-40 \%$ & Total bilirubin & 0.24 & $0.3-1.2 \mathrm{mg} / \mathrm{dL}$ \\
Monocytes & 6 & $2-9 \%$ & Cai+ & 1.11 & $1.11-1.4 \mathrm{mmol} / \mathrm{L}$ \\
Platelets & $627.10^{3}$ & $150-400 \times 10^{3} / \mathrm{mm}^{3}$ & &
\end{tabular}

$\mathrm{ALT}=$ alanine aminotransferase; $\mathrm{AST}$ = aspartate aminotransferase; Cai+ = ionized calcium; INR= international normalized ratio; $\mathrm{RV}=$ reference value .

The transabdominal pelvic ultrasonography showed an enlarged uterus (residual uterine volume $=705 \mathrm{~cm}^{3}$, reference value $(R V)^{*}=75.8 \mathrm{~cm}^{3}$ ) and heterogeneous myometrium with scattered multiple nodules. A submucosal fibroid in continuity with the cervix was expulsed into the vagina. No free liquid was observed into the recto-uterine pouch.

Under general anesthesia, the patient was submitted to curettage of the uterine cavity. The expulsed tumor plus the tissue removed by the procedure resulted in the 2000 grams of fetid bloody tissue, mixed with a purulent secretion (Figure 2).

\footnotetext{
* Mauad Filho F, Beduschi AF, Alberge R, et al. Avaliação ultra-sonográfica das variações do volume uterino. Rev Bras Ginecol Obstet [online]. 2001;23:175-9.
}

Because of extensive bleeding during the curettage, $600 \mathrm{~mL}$ of packed red blood cells were transfused. Ceftriaxone and metronidazole were prescribed.

Histological examination revealed spindleshaped cells neoplasm with moderate to severe cellular atypia, moderate cellularity, more than 10 mitoses per 10 high power fields, with extensive necrosis (Figures 3 and 4). The immunohistochemical panel (Table 2) associated with histological criteria favored the diagnosis of uterine leiomyosarcoma.

The patient presented an uneventful outcome, was discharged after 3 days of hospitalization and referred to an oncologic center. 
After 2 months, vaginal bleeding recurred, requiring hospitalization and packed red blood cells transfusion. The tumor staging workup showed the enlarged uterus with an infiltrative endometrial lesion, and non-calcified pulmonary nodules in the left upper lobe. Secondary involvement was highly suspected in the right lower lobe (Figures 5 and 6).
Aiming the control of pain and bleeding, panhysterectomy was carried out and chemotherapy with $100 \mathrm{mg} / \mathrm{m}^{2}$ docetaxel and $900 \mathrm{mg} / \mathrm{m}^{2}$ gemcitabine every 3 weeks was started. Size reduction of the pulmonary nodules was observed after 4 cycles of chemotherapy. The surgical specimen revealed a uterus weighing $875 \mathrm{~g}$ and measuring $13.0 \times 7.5 \times 6.0 \mathrm{~cm}$. A bosselated smooth nodule was identified in the lower portion

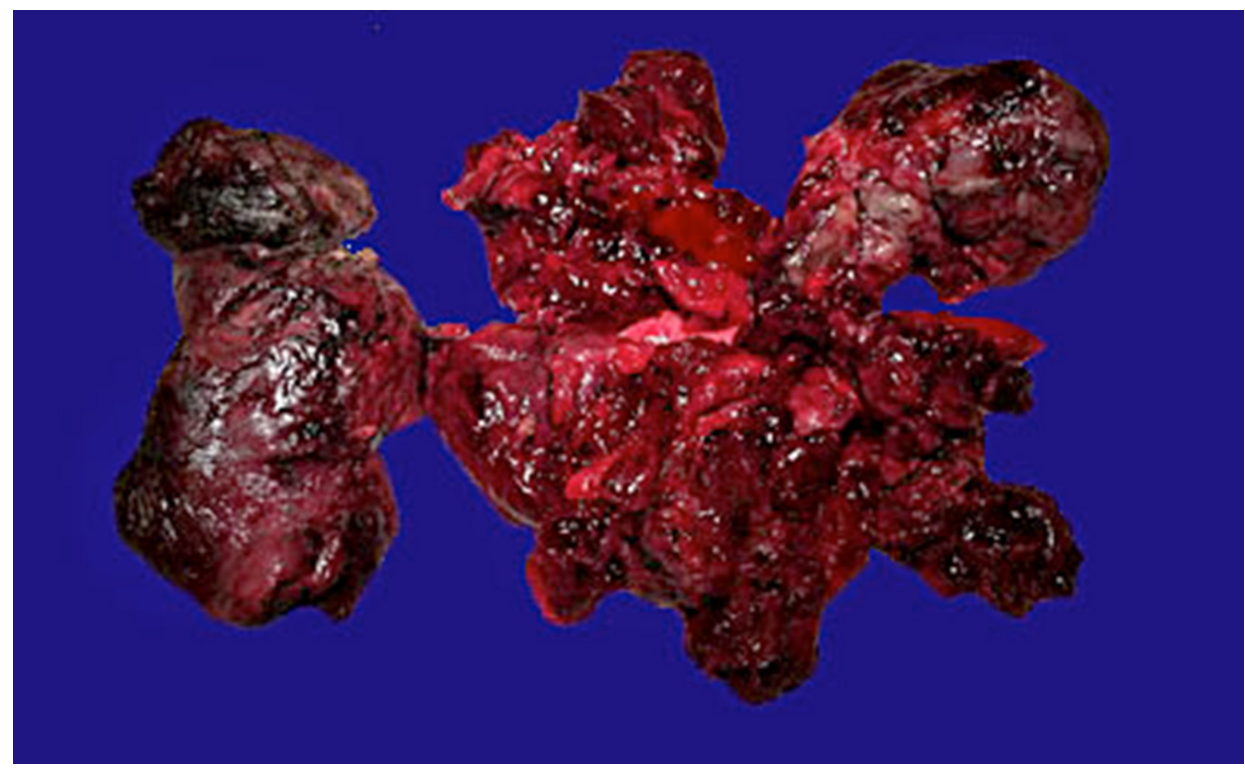

Figure 2 - Multiple irregular winy tissue fragments removed from the uterine cavity by curettage.

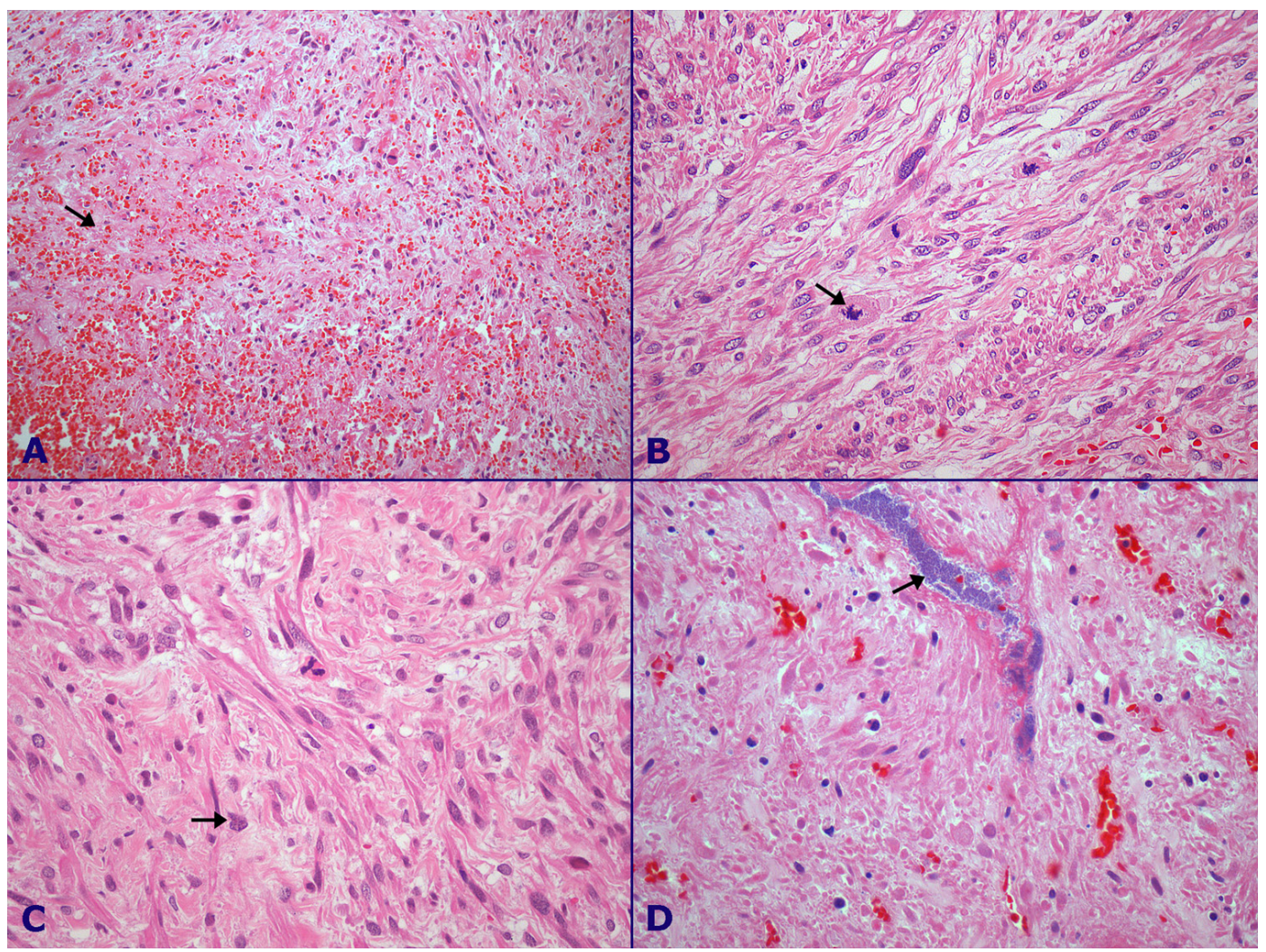

Figure 3 - Photomicrography of the expulsed tumoral mass. A - Overview of the leiomyosarcoma, showing pleomorphic hypercellular tissue with areas of necrosis (arrow), hemorrhage, (HE 100X); B - Numerous atypical mitosis (arrow), with over 15 mitoses/10 high power field (HE 400X); C - Intense nuclear pleomorphism (arrow) (HE 400X); D - Area of necrosis and bacterial proliferation, with colonies of bacteria (arrow). 


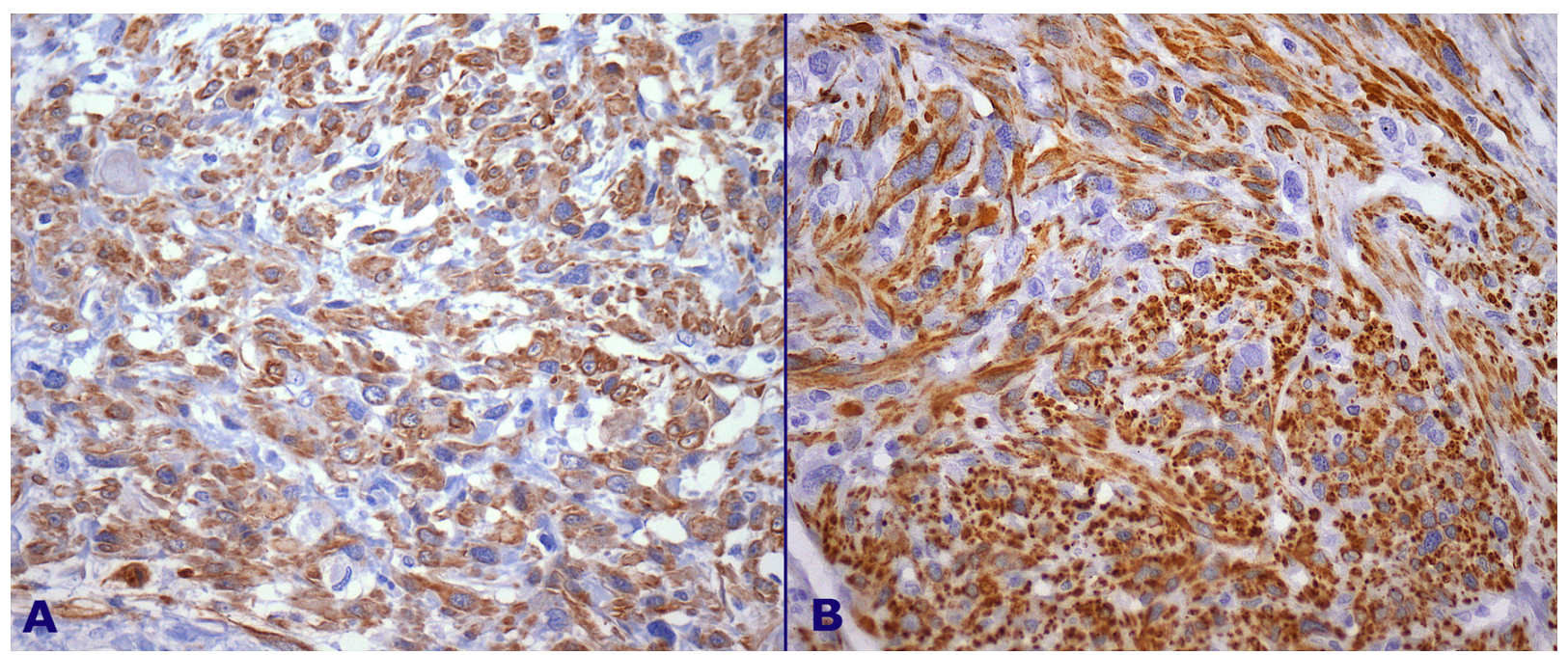

Figure 4 - Photomicrography of the expulsed tumoral mass - immunohistochemistry. A - Positive reaction for smooth muscle actin (HE 400X); B - Positive reaction for desmin (HE 400X).

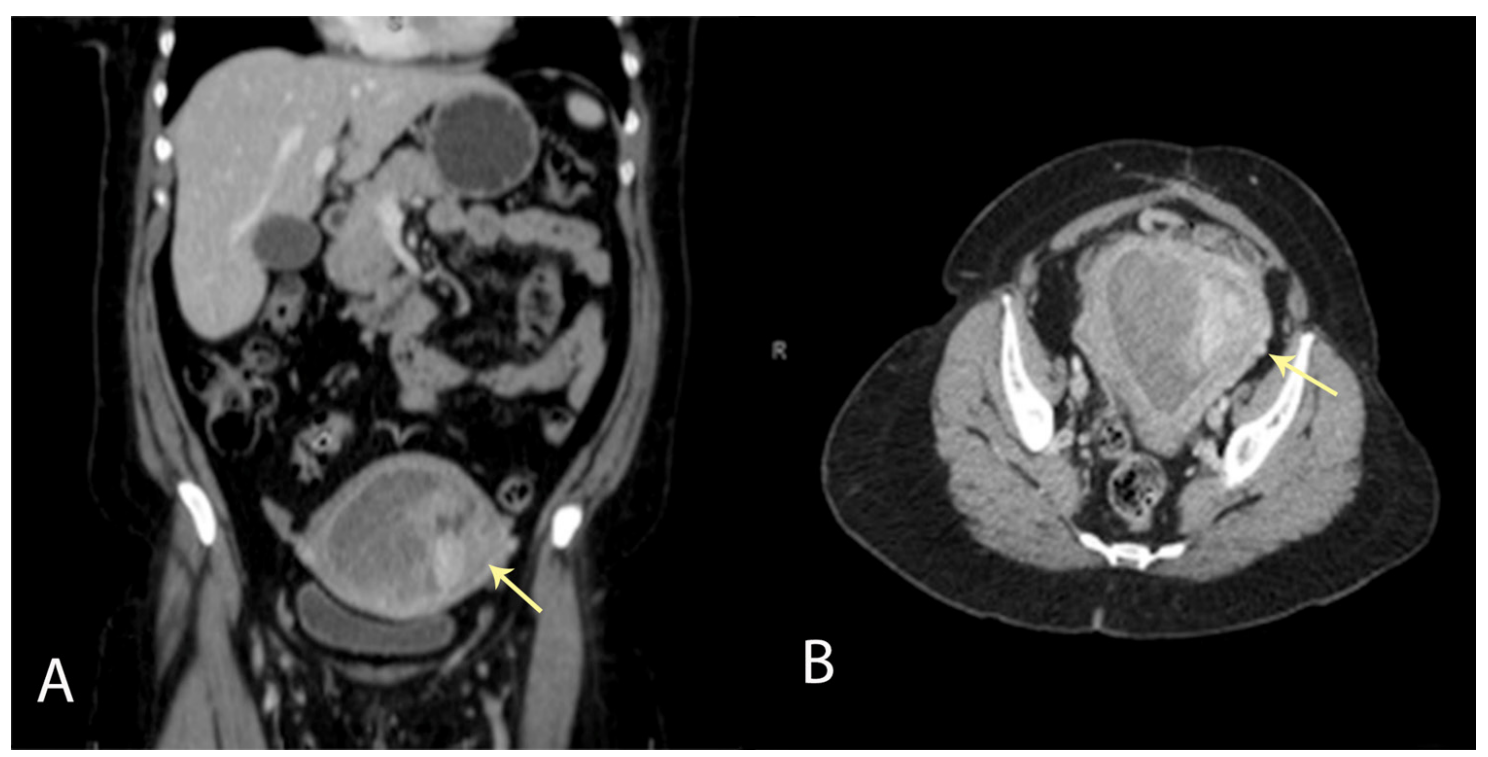

Figure 5-Abdominal end pelvic computed tomography. A - Coronal reformation showing increased uterine volume with tumoral invasion of the lateral wall of the uterus; B - Axial plane, showing in detail the tumoral infiltration of the uterine wall.

Table 2 - Immunohistochemical panel

\begin{tabular}{cccc}
\hline Antibody & Result & Antibody & Result \\
\hline S100 & Negative & CD34 & Negative \\
CD10 & Positive* $^{*}$ & CD117 & Inconclusive \\
Desmin & Positive & Ki67 & Positive 50\% \\
SMA & Positive & AE1/AE3 & Negative \\
\hline
\end{tabular}

$\mathrm{SMA}=$ smooth muscle actin; ${ }^{*}=$ Positive in rare cells.

of the uterus. Histologically, this mass proved to be a high-grade sarcoma with $14 \mathrm{~cm}$ in its longest axis, restricted to the uterus. The mitotic index was greater than 20 mitoses, necrosis was present, but angiolymphatic invasion was not detected. The ovaries and fallopian tubes were free of neoplasia.
The immunohistochemical panel results are shown in Table 3, and were compatible with the diagnosis of uterine leiomyosarcoma.

The patient is currently under treatment in the sixth cycle of chemotherapy, without respiratory symptoms, and presented no further episodes of bleeding

\section{DISCUSSION}

The uterine sarcomas are an uncommon and heterogeneous group of tumors of mesodermal origin, accounting for $3-7 \%$ of malignant tumors of the uterus and approximately $1 \%$ of all malignant tumors of the 


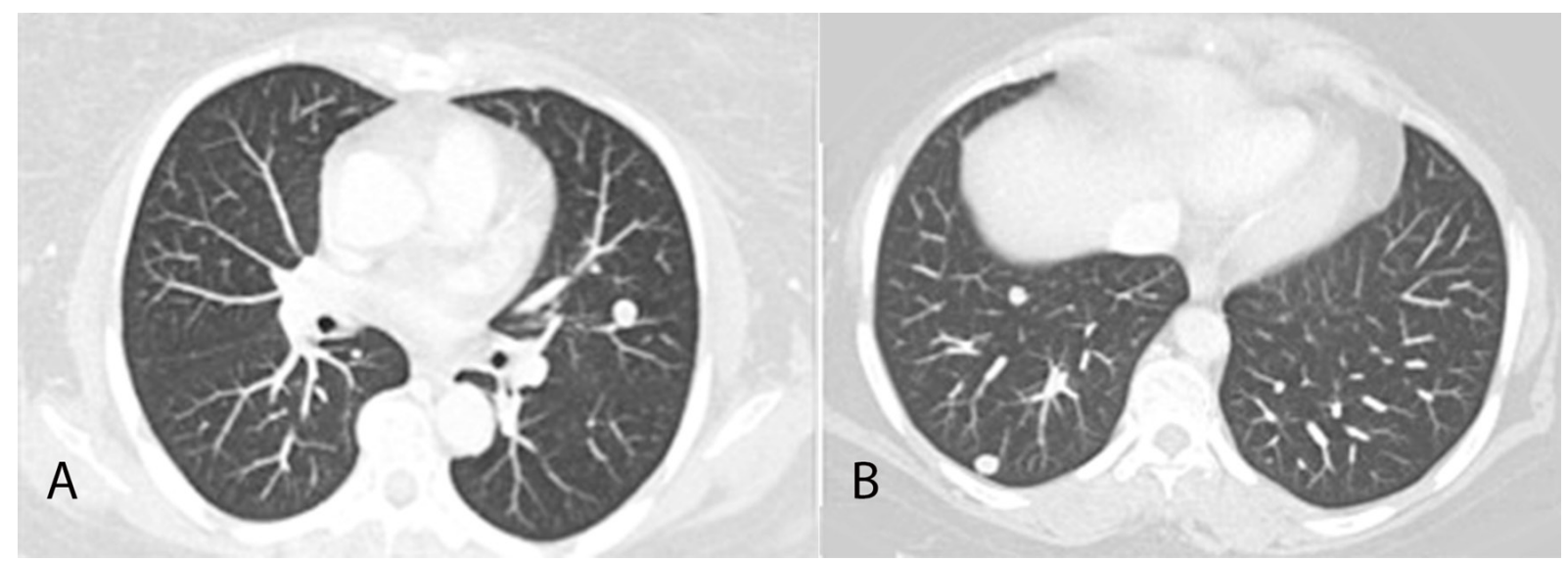

Figure 6 - A and B - Axial thoracic computed tomography. Lung window, showing scattered nodules throughout the lung parenchyma, compatible with metastases.

Table 3 - Immunohistochemical panel of the surgical specimen

\begin{tabular}{cccc}
\hline Antibody & Result & Antibody & Result \\
\hline SMA & Positive & Caldesmon & Focally Positive \\
CD10 & Positive & AE1/AE3 & Negative \\
Desmin & Negative & Pancytokeratin & Negative \\
\hline
\end{tabular}

SMA = smooth muscle actin.

female genital tract. Compared to endometrial tumors of epithelial origin, uterine sarcomas present more aggressive behavior and have a poor prognosis. In the U.S., the incidence of uterine sarcoma varies from 0.36 to $1.7 / 100,000$ women/year. ${ }^{1-4}$ The uterine sarcomas predominantly affect women from 40 to 60 years old, predominately in those of African descent. ${ }^{4}$ The average age at diagnosis is 55 years for leiomyosarcomas and 10 years later for the stromal sarcoma and endometrial carcinosarcoma. ${ }^{5}$

Similar to the uterus carcinomas, obesity, age (after menopause), and nulliparity are recognized as risk factors for uterine sarcomas, ${ }^{6}$ as well as previous pelvic irradiation, ${ }^{7}$ the use of tamoxifen, ${ }^{8}$ and genetic syndromes such as leiomyomatosis and hereditary renal carcinom. ${ }^{9-11}$

The histology of the main types of uterine sarcomas includes leiomyosarcoma (40\%), endometrial stromal sarcoma (10-15\%), and undifferentiated sarcoma (6\%). Other histologic types include adenosarcoma (5.5-9\%) and other rare uterine sarcomas, which are also classified as pure heterologous sarcomas (e.g. rhabdomyosarcoma, alveolar soft part sarcoma, angiosarcoma, liposarcoma, chondrosarcoma, and osteosarcoma). 1,12-14 The carcinosarcoma, also known as malignant mixed mullerian tumor, was formerly classified among malignant mesenchymal tumors of the uterine body, with an incidence of approximately $40 \% .{ }^{15}$ This neoplasia is rare, highly aggressive, and currently considered a metaplastic carcinoma and not another sarcoma. ${ }^{16}$ In the latest edition (2009) of the 'TNM Classification of Malignant Tumours'17, the same classification of uterine carcinoma was applied for Carcinosarcoma of the uterus. Based on molecular, epidemiological, genetic and histopathological data, most authors support the monoclonal hypothesis of the origin of this tumor, which states that primary malignant epithelial cells are presumably subjected to mesenchymal metaplasia..$^{18,19}$

Thus, leiomyosarcoma is the most common uterine sarcoma, which, in turn, is an aggressive tumor associated with a high risk of recurrence and death. ${ }^{9}$

Histologically, smooth-muscle tumors that show minimal or no atypia and are without coagulative necrosis, are classed as leiomyomas, regardless of mitotic count, whereas tumors showing moderate to severe atypia and coagulative necrosis are classed as leiomyosarcomas. ${ }^{20}$ Many characteristics are taken into account for malignancy diagnosis in leiomyosarcomas, including mitotic index, nuclear atypia, coagulative necrosis, cellularity, degree of differentiation and cellular pleomorphism, vascular invasion, and invasion of the surrounding myometrium. Among these histological characteristics, the mitotic index greater than 10 mitoses per 10 high-power fields, the degree of cytologic atypia, and the presence or absence of coagulative necrosis, are the most important predictors of the tumoral behavior. ${ }^{20,21}$ In a study comprising 28 cases of leiomyosarcomas, Jones and Norris (1995), ${ }^{22}$ showed that a tumor size greater than $3.0 \mathrm{~cm}$, and patient age greater than 50 years are also factors associated with a worse prognosis. 
Regarding the differential diagnosis between uterine sarcomas, the immunohistochemical study is of paramount importance. Among tumor markers that can be used in the panel, some are more specific for the diagnosis of leiomyosarcoma, such as smoothmuscle actin, desmin, histone deacetylase 8 (HDCA8), $\mathrm{h}$-caldesmon, and oxytocin receptor (oxytocin receptor). ${ }^{1,14,23-24}$ In the case reported here, beyond the morphological characteristics, presence of necrosis and high mitotic index, both immunohistochemical studies were compatible with the diagnosis of uterine leiomyosarcoma. While, in the specimen obtained by curettage, the positivity for SMA and Desmin support this diagnosis, in the specimen of the excised uterus the positivity for SMA and Caldesmon confirm the same diagnosis. The discrepancy between the results for Desmin may be explained by difference in material representation, it does not alter the final diagnosis.

The leiomyosarcoma commonly presents as a rapidly growing uterine mass. Abnormal uterine bleeding in pre- or postmenopausal women, in the form of menorrhagia, is the most common initial symptom. Pelvic pain, abdominal distension, urinary urgency and profuse and fetid leukorrhea are other common complaints. ${ }^{25}$ On physical examination, $70-80 \%$ of patients present increased uterine volume, which is often difficult to differentiate from a myomatous uterus. Clinical suspicion of uterine sarcoma should be suspected in the case of rapid growth of uterine volume.

The case reported here called attention to the unusual manifestation of leiomyosarcoma in a patient that was in amenorrhea for 2 years without a previous history of irregular bleeding. Despite the prior diagnosis of fibroids, amenorrhea associated with the vaginal expulsion of an amorphous bloody tissue raised the initial diagnosis of abortion in progress. This diagnosis was ruled out with a negative result of $\beta-H C G$ (human chorionic gonadotropin beta) and the ultrasound image of expulsed submucosal "fibroid." Thus, the first hypothesis in this case was vaginal fibroid expulsion.

The ultrasonographic pelvic examination that showed increased uterine volume and diffuse heterogeneity of the myometrium did not allow the diagnosis of leiomyosarcoma to be considered. Information on tumor bizarre architecture and its vasculature as well as the diastolic flow and resistance indices, analyzed through ultrasound with Doppler or magnetic resonance imaging (MRI), could contribute to the increased likelihood of a diagnosis of uterine sarcoma. ${ }^{26}$
Leiomyosarcoma develops from smooth muscle and only $30 \%$ of cases are submucosal in origin, which may explain the unusual presentation of this case report. ${ }^{26}$ Sarcoma expulsion is most often seen in cases of adenosarcoma, a rare cancer of polypoid pattern originated from the endometrium. This sarcoma may be expulsed through the cervical orifice when the tumor size assumes large proportions. ${ }^{27}$

Diagnosis can be made by biopsy or endometrial curettage or, with some frequency, by histopathology fragment of polypoid mass expulsed by the cervix as seen in this case report. However, in retrospective series, the sensitivity of this diagnostic approach was about $60 \%$. Therefore, the diagnosis is usually confirmed after hysterectomy. ${ }^{28}$

The low incidence, clinical diversity behavior, and histology of uterine sarcomas contribute to the lack of consensus on their treatment, which can vary according to the type of sarcoma, its stage, and the patient's age. ${ }^{13}$ Local recurrence, and hematogenic spread to the lungs are common, as was observed in this case. The treatment of choice for gynecological sarcomas is a total hysterectomy accompanied by oophorectomy, lymphadenectomy, and cytological evaluation of peritoneal fluid. However, in the case of young patients, this approach is still under debate.

Giuntoli et al. ${ }^{10}$, in reviewing 208 patients with the diagnosis of uterine leiomyosarcoma, observed that the degree of tumor differentiation and advanced stage of disease were the main prognostic factors that could affect the patient's survival rate. Moreover, they observed a significant reduction in the rate of recurrence with the use of adjuvant radiotherapy, without affecting overall survival. Regarding the preservation of the ovaries, there was no difference in survival or recurrence rates. Finally, there was no difference in the rate of survival among patients who underwent lymphadenectomy. Adjuvant chemotherapy with docetaxel and gemcitabine for four cycles is an option for treatment of tumors that invade the body and cervix of the uterus. ${ }^{29}$

The treatment for metastatic disease is based on chemotherapy. A Phase II study of 29 patients with leiomyosarcoma showed a 10\% complete response rate and a $43 \%$ partial response rate when treated with a combination of gemcitabine and docetaxel. The overall survival time was 17.9 months. ${ }^{30}$

In the case of localized leiomyosarcoma, hysterectomy is the treatment of choice. In these cases, 
and in younger patients, the ovaries are preserved. In locally advanced disease or in post-menopausal patients, most studies showed no difference in the survival rate between those whose ovaries are retained and those who undergo a bilateral oophorectomy. ${ }^{31}$

\section{CONCLUSION}

Uterine sarcomas are rare neoplasia characterized by aggressiveness and poor prognosis. In the absence of prospective randomized trials, treatment recommendations are based on the results of retrospective reviews. Total hysterectomy remains the treatment of choice and may be associated, depending on the case, to bilateral salpingooophorectomy. Adjunctive therapy, such as radiation and chemotherapy, appears to reduce local recurrence; however, no survival benefit has been demonstrated.

Despite the rarity of this tumor, uterine sarcomas should be considered as a differential diagnosis in patients with uterine masses, pelvic pain, or bleeding.

The identification of the disease in its early stages, liable to curative resection, is extremely important. Otherwise, in advanced cases, the prognosis is poor, even with the complementary chemotherapy.

\section{REFERENCES}

1. D’Angelo E, Prat J. Uterine sarcomas: a review. Gynecol Oncol. 2010;116:131-9. PMid:19853898. http://dx.doi. org/10.1016/j.ygyno.2009.09.023

2. Reed NS. The management of uterine sarcomas. Clin Oncol (R Coll Radiol). 2008;20:470-8. PMid:18572394. http://dx.doi. org/10.1016/j.clon.2008.04.002

3. Greer BE, Koh WJ, Abu-Rustum N, et al. Uterine cancers. J Natl Compr Canc Netw. 2006;4:438-62. PMid:16687093.

4. Toro JR, Travis LB, Wu HJ, Zhu K, Fletcher CD, Devesa SS. Incidence patterns of soft tissue sarcomas, regardless of primary site, in the surveillance, epidemiology and end results program, 1978-2001: An analysis of 26,758 cases. Int J Cancer. 2006;119:2922-30. PMid:17013893. http:// dx.doi.org/10.1002/ijc.22239

5. Tinkler SD, Cowie VJ. Uterine sarcomas: a review of the Edinburgh experience from 1974 to 1992 . Br J Radiol. 1993;66:998-1001. http://dx.doi.org/10.1259/00071285-66-791-998
6. O'Meara AT. Uterine sarcomas: have we made any progress? Curr Opin Obstet Gynecol. 2004;16:1-4. PMid:15128000. http://dx.doi.org/10.1097/00001703-200402000-00002

7. Nickie-Psikuta M, Gawrychowski K. Different types and different prognosis-study of 310 uterine sarcomas. Eur $\mathrm{J}$ Gynaecol Oncol. 1993;14(Suppl):105-13. PMid:8200360.

8. Arenas M, Rovirosa A, Hernández V, et al. Uterine sarcomas in breast cancer patients treated with tamoxifen. Int J Gynecol Cancer. 2006;16:861-5. PMid:16681774. http://dx.doi. org/10.1111/j.1525-1438.2006.00415.x

9. Moinfar F, Azodi M, Tavassoli FA. Uterine sarcomas. Pathology. 2007;39:55. PMid:17365823. http://dx.doi. org/10.1080/00313020601136146

10. Giuntoli RL 2nd, Metzinger DS, DiMarco CS, et al. Retrospective review of 208 patients with leiomyosarcoma of the uterus: prognostic indicators, surgical management, and adjuvant therapy. Gynecol Oncol. 2003;89:460-9. http:// dx.doi.org/10.1016/S0090-8258(03)00137-9

11. Launonen V, Vierimaa O, Kiuru M, et al. Inherited susceptibility to uterine leiomyomas and renal cell cancer. Proc Natl Acad Sci USA. 2001;98:3387-92. PMid:11248088 PMCid:30663. http://dx.doi.org/10.1073/pnas.051633798

12. Clement $\mathrm{P}$, Oliva $\mathrm{E}$. Mesenchymal lesions of the uterus. Histopathology. 2002,41(Suppl. 2),12-31. http://dx.doi. org/10.1046/j.1365-2559.41.s2.33.x

13. Tropé CG, Abeler VM, Kristensen GB. Diagnosis and treatment of sarcoma of the uterus. A review. Acta Oncol. 2012;51:694-705. PMid:22793037. http://dx.doi.or $\mathrm{g} / 10.3109 / 0284186 X .2012 .689111$

14. McCluggage WG, Robboy SJ. Mesenchymal uterine tumors, other than pure smooth muscle neoplasms, and adenomyosis. In: Robboy SJ, mutter GL, Prat J, Bentley RC, Russell P, Anderson MC, editors. Robboy's pathology of the female reprodutive tract. 2nd ed. Philadelphia: Churchill Livingstone, Elsevier; 2009. p. 431. http://dx.doi.org/10.1016/B978-0443-07477-6.50022-6

15. Koivisto-Korander R, Butzow R, Koivisto AM, Leminen A. Immunohistochemical studies on uterine carcinosarcoma, leiomyosarcoma, and endometrial stromal sarcoma: expression and prognostic importance of ten different markers. Tumour Biol. 2011;32:451-9. PMid:21161468. http://dx.doi. org/10.1007/s13277-010-0138-1

16. El-Nashar SA, Mariani A. Uterine carcinosarcoma. Clin Obstet Gynecol. 2011;54:292-304. PMid:21508698. http:// dx.doi.org/10.1097/GRF.0b013e31821ac635

17. Sobin LH, Gospodarowicz MK, Wittekind Ch, International Union Against Cancer (UICC), editors. TNM classification of malignant tumours. 7th ed. Hoboken: WileyBlackwell; 2009. 310 p.

18. Kernochan LE, Garcia RL. Carcinosarcomas (malignant mixed Mullerian turmor) of the uterus: advances in elucidation 
of biologic and clinical characteristics. J Natl Compr Canc Netw. 2009;7:550-6. PMid:19460280.

19. Gorai I, Yanagibashi T, Taki A, et al. Uterine carcinosarcoma is derived from a single stem cell: an in vitro study. Int J Cancer.1997;72:821-7. http://dx.doi.org/10.1002/(SICI)10970215(19970904)72:5<821::AID-IJC19>3.0.CO;2-B

20. Quade BJ, Robboy SJ. Uterine smooth muscle tumors. In: Robboy SJ, Mutter GL, Prat J, Bentley RC, Russell P, Anderson MC, editors. Robboy's pathology of the female reprodutive tract. 2nd ed. Philadelphia: Churchill Livingstone/ Elsevier; 2009. p.474-8. http://dx.doi.org/10.1016/B978-0443-07477-6.50023-8

21. Silva ASL, El Ibrahim R. Neoplasias mesenquimais do corpo uterino. In: Maluf FC, Azevedo FC, Souza CE, Saragiotto DF, editors. Cancer ginecológico. São Paulo: Dendrix Edição e Design Ltda; 2010. p. 265-75. Portuguese.

22. Jones MW, Norris HJ. Clinicopathologic study of 28 uterine leiomyosarcomas with metastasis. Int J Gynecol Pathol. 1995;14:243-9. http://dx.doi.org/10.1097/00004347199507000-00008

23. O'Neill CJ, McBride HA, Connolly LE, McCluggage WG. Uterine leiomyosarcomas are characterized by high p16, p53 and MIB1 expression in comparison with usual leiomyomas, leiomyoma variants and smooth muscle tumours of uncertain malignant potential. Histopathology. 2007;50:8518. PMid:17543074. http://dx.doi.org/10.1111/j.13652559.2007.02699.x

24. Abeler VM, Nenodovic M. Diagnostic immunohistochemistry in uterine sarcomas: a study of 397 cases. Int J Gynecol Pathol. 2011;30:236-43. PMid:21464730. http://dx.doi. org/10.1097/PGP.0b013e318200caff
25. Leung F, Terzibachian JJ, Aouar Z, Govyadovskiy A, Lassabe C. Uterine sarcomas: clinical and histopathological aspects. Report on 15 cases. Gynecol Obstet Fertil. 2008;36:62835. PMid:18538624. http://dx.doi.org/10.1016/j. gyobfe.2008.03.012

26. Gandolfo N, Gandolfo NG, Serafini G, Martinoli C. Endometrial stromal sarcoma of the uterus: MR and US findings. Eur Radiol. 2000;10:776-9. PMid:10823632. http://dx.doi. org/10.1007/s003300051003

27. Clement PB, Scully RE. Mullerian adenosarcoma of the uterus: a clinicopathologic analysis of 100 cases with a review of the literature. Hum Pathol. 1990;21:363-81. http:// dx.doi.org/10.1016/0046-8177(90)90198-E

28. Bansal N, Herzog TJ, Burke W, et al. The utility of preoperative endometrial sampling for the detection of uterine sarcomas. Gynecol Oncol. 2008;110:43. PMid:18445505. http://dx.doi. org/10.1016/j.ygyno.2008.02.026

29. Hensley ML. Uterine/female genital sarcomas. Curr Treat Options Oncol. 2000;1:161-8. PMid:12057054. http://dx.doi. org/10.1007/s11864-000-0061-6

30. Hensley ML, Maki R, Venkatraman E, et al. Gemcitabine and docetaxel in patients with unresectable leiomyosarcoma: results of a phase II trial. J Clin Oncol. 2002;20:2824-31. PMid:12065559. http://dx.doi.org/10.1200/JCO.2002.11.050

31. Kapp DS, Shin JY, Chan JK. Prognostic factors in survival in 1396 patients with uterine leimiosarcoma: emphasis on impact of lymphadenectomy and oophorectomy. Cancer. 2008;112:820-30. PMid:18189292. http://dx.doi. org/10.1002/cncr.23245

\section{Conflict of interest: None}

Submitted on: $7^{\text {th }}$ February 2012

Accept on: $20^{\text {th }}$ May 2012

\section{Correspondence:}

Rua Três de Maio, 154 apto 61- Vila Clementino - São Paulo/SP - Brazil

CEP: 04044-020 - Phone: +55 (11) 99932-9423

E-mail: ricardossimoes@hotmail.com 